\title{
EDUCAÇÃO E SOCIEDADE: UM ESTUDO EXPLORATÓRIO ACERCA DOS MEANDROS DA VIOLÊNCIA JUVENIL
}

\author{
A. A. SOUZA \\ Universidade Federal do Rio Grande do Norte - UFRN \\ drycacyda@yahoo.com.br*
}

Artigo submetido em julho/2015 e aceito em julho/2015

DOI: $10.15628 /$ holos.2015.3197

\section{RESUMO}

A proposição básica deste artigo é apresentar um estudo exploratório acerca de violência e sociedade com ênfase em estudos sobre violência juvenil. Objetiva-se, assim, compreender o fenômeno da violência de forma situada nos espaços nos quais os jovens se inserem no Brasil, visando detectar os prolegômenos que incidem sobre as práticas de violência: sofrida e cometida por jovens. Assim, apreende-se a problemática que envolve a violência em suas diversas modalidades e dimensões, inserida no contexto histórico das sociedades do Século
$\mathrm{XXI}$, por meio de estudos em autores que discutem sobre o tema no cenário mundial e brasileiro; bem como apresentando dados disponibilizados em domínio público sobre violência e sociedade no Brasil. Considera-se que, a violência vivenciada pelos jovens tem consequências e repercussões em suas vidas e na sociedade. Desse modo, requer compreendê-la como prática social aética, como um impedimento de fato; uma ação contrária a qualquer processo socializador.

PALAVRAS-CHAVE: Educação; Violência; Juventude; Socialização; Práticas violentas.

\section{EDUCATION AND SOCIETY: AN EXPLORATORY STUDY ABOUT THE MEANDERS OF YOUTH VIOLENCE}

\begin{abstract}
The basic proposition of this article is to present an exploratory study on violence and society with emphasis on studies on youth violence. The purpose is thus to understand the phenomenon of violence located in the spaces where young people fall in Brazil in order to detect the prolegomena that focus on the practices of violence: suffered and committed by young people from. So, learn to issues involving violence in its diverse forms and dimensions, inserted in the historical context of societies
\end{abstract}

of the XXI Century, through studies on authors who discuss the subject in the world and Brazilian scene; as well as presenting data available in the public domain on violence and society in Brazil. It is considered that the violence experienced by young people has consequences and repercussions in their lives. Thus requires understanding it as a social and ethic practice, an impediment in fact; a contrary action to any socializing process.

KEYWORDS: Education; Violence; Youth; Socialization; Violent practices. 


\section{INTRODUÇÃO}

A proposição deste artigo é fazer uma análise exploratória acerca da violência sofrida e praticada por jovens. Problematizamos esta realidade, inserindo-a na sociedade brasileira, pois objetiva-se compreender o fenômeno da violência visando detectar os prolegômenos que incidem sobre as práticas de violência: sofrida e cometida por jovens. Tendo como material de análise dados estatísticos sobre a violência praticada e sofrida pelos jovens no Brasil no intuito de apreender como as medidas de proteção e/ou as medidas socioeducativas dos jovens em conflito com a lei são discutidas em nossa sociedade.

Acredita-se que a violência vivenciada pelos jovens tem consequências e repercussões em suas vidas e na sociedade. Sendo assim, é preciso ressaltar que a violência sobre a se reflete neste trabalho busca compreendê-la como prática social aética, como um impedimento de fato; uma ação contrária a qualquer processo socializador e solidário, posto que a violência é contrária à perspectiva de cuidado com o outro.

Considera-se que, as ações violentas praticadas ou sofridas por jovens no Brasil é um aporte de pesquisa que pode ser problematizado a partir de referenciais bibliográficos, e também de dados estatísticos que dão conta de uma realidade social pouco estudada. Postula-se desse modo, colocar em discussão pesquisas que busquem compreender o fenômeno da violência sem descuidar dos sujeitos protagonistas das ações. Isto é, compreender um universo complexo e multifacetado, que tem suas raízes nos primórdios de nossa sociedade como República, e que impera nas relações de sociabilidade da juventude na atualidade em todas as dimensões da vida social.

Nessa perspectiva, é relevante apreender a violência juvenil em dois aspectos diferentes, mas não sem interligação, pois se acredita que a violência sofrida pelos jovens em sua infância se expressa e é ampliada na juventude. Sendo assim, é necessário analisar o processo de desenvolvimento da infância para compreender a juventude.

\section{CONTEXTUALIZANDO A VIOLÊNCIA JUVENIL}

A natureza instrumental da violência é analisada por Arendt (2004) ao refletir sobre esta. Para ela, uma ação violenta é sempre regida pela categoria meio-fim. Assim, como meio, pode ser vista, como um instrumento que depende de orientação e de justificativa para um fim que se objetiva alcançar. Para esta pensadora, sendo a violência uma das manifestações das relações sociais, está a serviço de uma forma de organização da vida, ou seja, de um modelo de sociabilidade que nas sociedades capitalistas se dão em meio a relações sociais contraditórias. Este, entendido como um processo construído pelos homens para viver em sociedade, que como diz Bauman (1998) deve ser compreendido a partir da interação com a estrutura social, na qual os indivíduos compartilham ações baseadas no instante em que se vive, e nas condições semelhantes nas quais se encontram.

A violência ganha diferentes formas e significados, de acordo com os valores culturais e ideológicos de cada sociedade, bem como das condições sociais, técnicas, tecnológicas, culturais e históricas. Essa está presente tanto em atos que se expressam de forma institucionalizada como 
em atos interpessoais praticados por cidadãos comuns, conforme Ferreira (2002). Todavia, para uma reflexão situada sobre violência é necessário entender a dinâmica dessa violência e como esta é produzida na sociedade; como essa sociedade a constitui em suas relações sociais, econômicas e culturais.

A sociedade brasileira tem apresentado nos anos iniciais do século XXI, um alto índice de violência contra crianças praticada no contexto familiar. Dessa forma, pode-se verificar que no processo socializador da infância no Brasil a violência é um ato presente. O Instituto de Pesquisa e Estatística Aplicada (IPEA, 2003 apud FALLUH, 2004), vinculado ao Ministério do Planejamento, Orçamento e Gestão do Brasil, informa que $84,8 \%$ de um total de 19.373 dos abrigamentos decorrem de violência intrafamiliar infringida pelos responsáveis pela criança. Observe-se que este Índice por si, já denota que, a questão deve ser considerada em estudos sobre a criança no país. Não apenas porque a criança é um ser humano em processo de desenvolvimento em todos os aspectos da vida psíquica e social, mas, porque nas crianças se encontra o jovem e o cidadão do futuro e também a esperança de que um outro mundo é possível, se utilizarmos expressões formuladas por Boch (2005) e Santos (2004).

A violência em suas mais diversas manifestações (física, sexual, simbólica, psicológica e as vinculadas à negligência) é uma ação humana inaceitável, notadamente se praticada contra seres indefesos. Entretanto, estas ações encontram-se presentes na sociedade brasileira e nas demais sociedades contemporâneas.

Assim sendo, a compreensão deste estudo sobre violência ampara-se no conceito desenvolvido por Chauí (2006, p. 342) que a define como todo ato contrário à ética, praticado contra alguém, e "caracteriza-se por relações intersubjetivas e sociais definidas pela opressão, intimidação, pelo medo e pelo terror". Essa autora argumenta também que, quando uma cultura e uma sociedade definem o que entendem por mal, crime e vício, circunscrevem aquilo que julgam violento - contra um indivíduo, ou contra um grupo. Simultaneamente, elegem os valores positivos que irão definir o bem e a virtude, como barreiras éticas contra a violência.

Seguindo esta concepção, pode-se entender o bem como aquilo que cuida satisfatoriamente da vida em sociedade, possibilitando a existência com dignidade e permitindo que se construam laços afetivos que garantam o convívio social. Tudo isso não pode ser circunscrito como violência, pois este entendimento é contrário, portanto, aos atos que possam prejudicar a construção desses laços. Logo, as práticas violentas impedem e se tornam um empecilho ao processo social como modo civilizatório de constituição de uma ética humanizadora; de uma formação humana em sentido pleno.

Reconhece-se que, no início do Século XXI, existe uma grande preocupação com os índices de crescimento da violência em suas diferentes formas de manifestação. Pode-se até propor que esta é uma questão primordial para reflexões acadêmicas e científicas sobre a sociedade brasileira, posto que na atualidade o problema da violência tem ocupado não só acadêmicos, mas, setores organizados da sociedade civil, instituições estatais, e também o cidadão comum. Esse fenômeno pode ser visto como um problema universal, tendo configurações particulares em tempos, lugares e contextos específicos. Diante disto, pode-se questionar: por que a sociedade brasileira traz em suas estatísticas altos índices de violência praticados e sofridos por jovens?

De acordo com Kaufman (1997, p. 32) a existência das práticas de castigos nas culturas humanas faz parte da crença existente e mantida por elas, para educar os indivíduos, 
condicionando-os a seguir as leis sociais. Os castigos são aplicados e aceitos, pois há entendimento de que, só com o exemplo haverá obediência às leis, às normas e aos costumes. Isto leva à "cultura do medo", que faz com que todos aceitem como necessária e legítima a utilização da violência sobre o corpo. Não se observa que este é um modelo de violência que pode se expressar fora do espaço familiar.

A violência expressa relações sociais, bem como relações intersubjetivas que podem ser verificadas entre homens e mulheres, entre adultos e crianças e/ou jovens, bem como, jovens e outras instâncias como o patrimônio público, outros jovens etc. Nota-se que seu resultado mais visível é a conversão de sujeitos em objetos. Essa está enraizada no modo como os homens produzem e reproduzem suas condições de existência social. Ela é expressão de padrões de sociabilidade, de modos de vida e de modelos de comportamento existentes numa sociedade em um determinado período histórico. Para Guerra (1998), interpretando Adorno (1988), se se observar esses aspectos em uma determinada sociedade dentro de uma abordagem histórica pode-se visualizar como essa foi constituída como cultura da violência; ora legitimados, ora condenados.

É na perspectiva teórico-conceitual desenvolvida por esses autores que se considera que, a violência pode ser estudada tendo como locus de apreensão as relações sociais, os ambientes de sociabilidade como instituições familiares, escolas, a rua e a própria sociedade; pensando-a como fenômeno cultural pleno de significados sociais e humanos. Essa propositiva é ensejada pela percepção de que as sociedades contemporâneas tem produzido e reproduzido cenas de violência, tanto na esfera pública como privada, e também pela mídia, atingindo todos os segmentos sociais. É, assim, um fenômeno universal que está presente na história humana em todas as sociedades.

Autores como Maldonado e Williams (2005) enfatizam isto em seus estudos quando fazem uma revisão bibliográfica das pesquisas realizadas sobre os efeitos da violência doméstica sobre o desenvolvimento de crianças e adolescentes. De acordo com essas pesquisas, o fato de presenciar violência doméstica poderia causar dificuldades de comportamento sociáveis nas crianças e adolescentes. Essas foram ilustradas em um estudo comparativo como pertencentes à famílias violentas, não-violentas e com estresse maternal, indicando que há uma significativa prevalência de problemas comportamentais e reduzida competência social em crianças e jovens expostos à violência familiar. (WOLFE, JAFFE, WILSON \& ZAK, 1985 apud, MALDONADO e WILLIAMS, 2005).

Esses resultados ainda confirmam e dão embasamento à posição de Cummings (1998) que discute as diretrizes conceituais e teóricas sobre crianças expostas ao conflito conjugal e à violência. Esta autora ressalta a posição de Bandura (1973) de que as crianças podem aprender modelos cognitivos e comportamentais a partir de modelos ou cópias de eventos diários, incluindo-se nesses, suas observações do comportamento de seus pais. Para ela a família é responsável pela aquisição de modelos agressivos pelas crianças. (BANDURA, 1973; JAFFE, WOLFE, \& WILSON, 1990; GOMIDE, 2003 apud, MALDONADO e WILLIAMS, 2005). Desse modo, os pais que utilizam a punição violenta estão mostrando a seus filhos que a violência é uma forma apropriada de resolução de conflitos e de relacionamento entre os indivíduos, inclusive, uma maneira de educar pelo domínio violento sobre o outro que pode perdurar por toda vida.

Ainda de acordo com Maldonado e Williams (2005) essa propositiva corrobora a de Graham-Bermann (1998) exposta em seu trabalho sobre o impacto da violência contra a mulher no desenvolvimento social da criança. Assinala esse autor que, os modelos de comportamento 
aprendidos na primeira infância em interações com os outros são automaticamente usados em novas situações quando jovens. Assim, defende que seria por meio dessa aprendizagem, que a criança adicionaria táticas de agressão, podendo aprender a manipular, persuadir e coagir, tendendo a mostrar, desde o início, comportamentos antissociais, podendo ainda exibi-los em interações sociais com os outros, fora do ambiente familiar, na escola, por exemplo. 0 comportamento agressivo, segundo os estudos acima citados, está inserido entre os problemas apresentados pelas crianças frente à violência seja doméstica ou intrafamiliar e podem se manifestar na fase seguinte, qual seja, da juventude.

Para Maldonado e Williams (2005), baseadas em outros estudos sobre a temática, os resultados mostram a possível relação entre violência doméstica e comportamento agressivo, entre tais estudos encontra-se o de Meneghel, Giugliani e Falceto (1998) que se dedicaram a relação entre violência doméstica e agressividade na adolescência, em um estudo comparativo entre alunos considerados agressivos e não-agressivos de duas escolas (pública e privada), da cidade de Porto Alegre. Os resultados indicaram que em ambas as escolas existiam famílias com episódios graves e frequentes de punição em proporção semelhante. E que os adolescentes considerados agressivos na escola eram mais punidos do que os adolescentes não-agressivos. Ressaltam os autores que "ficou explícita a figura do adolescente agressivo e maltratado, violento e machucado," como resultante de relações agressivas no espaço familiar. (MENEGHEL, e COLS., apud, MALDONADO e WILLIAMS, 2005, p. 04). Então, pode-se compreender que a violência não se situa apenas em um dos espaços relacionais vivido pelos jovens.

A história dos jovens no Brasil é marcada por imagens preconceituosas e discriminatórias. Historicamente, a trajetória dos jovens foi configurada por denominações estigmatizantes (desvalidos, vadios, vagabundos, menores delinquentes, marginais, bandidos, pivetes, trombadinhas, carentes, meninos de rua etc.). Nesse sentido, enfatiza Evangelista (2007) que a vida dos jovens no contexto histórico-social ao longo dos séculos no nosso país tem sido marcada por rótulos originários de ideias estereotipadas introduzidas por agentes das políticas públicas e órgãos do Judiciário que talvez por desconhecimento do contexto e do desenvolvimento humano criaram expressões para representar esses jovens. Diz ainda que, a Igreja Católica contribuiu com esse olhar para os jovens através das Santas Casas de Misericórdia, que se propunham a assistir meninos pobres, vadios, desvalidos e delinquentes.

Ainda de acordo com Evangelista (2007, p. 10) o Código de Menores, de 1929, já destacava o problema do menor a partir da correção "educar e disciplinar física, moral e civicamente o menor, visto como produto de pais vadios, pobres, irresponsáveis, ou resultante da orfandade." Entendiase assim, que este problema era fruto da orfandade e da irresponsabilidade das famílias pobres. $O$ autor enfatiza ainda que já na segunda metade do século XX, durante o

golpe civil/militar, de 1964, com a criação da Fundação Nacional do Bem-Estar do Menor (FUNABEM), identificou-se um processo de ampliação da presença estatal na formação da política social que caracterizou o período autoritário pós-1964, quando os interesses das comunidades foram excluídos dos processos decisórios e submetidos a um controle sistemático, inspirado nos princípios da doutrina de segurança nacional, preconizada pela Escola Superior de Guerra (ESG). (EVANGELISTA, 2007, p. 10). 
Pode-se interpretar que em todo o processo histórico da sociedade brasileira foi caracterizado ou delegado aos jovens pobres a responsabilidade pela violência, crime, vadiagem etc. Não se reconhecendo que esta situação é influenciada pela desigualdade social. Assim, foi se constituindo o que atualmente se ler como violência juvenil e que assume diferentes feições: crime organizado, guerra do tráfico, arrastões, entre outras. Nesse contexto, os jovens passam a ser protagonistas e também vítimas da violência que vem sendo construída historicamente.

Abramovay e Feffermann (2014) argumentam que a relação de dominação no cotidiano desses jovens é marcada pela busca de um lugar no grupo, e muitas vezes, esse lugar se encontra no tráfico de drogas, um lugar de destaque no contexto de vida dos jovens da periferia das grandes cidades. Reproduz-se assim, na cultura do tráfico de drogas, a relação de dominação a que são submetidos na sociedade em geral.

Desse modo, os jovens passam a ser associados à rebeldia, condição que é acirrada quando alguns grupos juvenis expressam atitudes que podem ressignificar normas e padrões sociais vigentes.

Nota-se no Brasil um aumento no número de adolescentes em conflito com a lei como se pode identificar na pesquisa realizada por Dalmo Evangelista (2007) que afirma crescer o número de adolescentes infratores internados para cumprir medidas socioeducativas. Ainda de acordo com esse autor, em uma pesquisa divulgada pela Secretaria de Direitos Humanos (SEDH) o total de internos no sistema socioeducativo cresceu $28 \%$ entre 2002 e 2006. Isso significa que havia, no Brasil, nesse período 15.426 jovens cumprindo pena com algum tipo de restrição, dos quais $68 \%$, em regime de internação.

A violência constitui, assim, nesta perspectiva, toda uma justificativa, que se institucionaliza nas ações de forma cristalizada. Dessa forma, pelas razões teóricas e empíricas apresentadas os valores da violência se constituem como consagrados para determinado grupo social, pois envolvem relações sociais e formas de sociabilidade - como já enfatizado.

Sendo assim, podemos dizer que a violência por se apresentar como uma ação naturalizada dos indivíduos, em certos grupos sociais - aparece como se não fosse violência à ação prática do sujeito/jovem violento, bem como a violência sofrida pelos jovens. $E$ ainda, por reconhecer que os valores e costumes de uma sociedade influenciam a construção de comportamentos violentos, deixando vulneráveis, as crianças e os jovens. Sabendo-se que esses afetam seu crescimento e desenvolvimento como seres humanos e sociais, portadores de sentido e, de significados construídos nas relações sociais.

Nessa linha de raciocínio entende-se que a violência é um fenômeno que pode ser percebido em todas as sociedades dos primórdios até o século XXI e refere-se a uma conduta de abuso de poder, que envolve situações de força, de tensão e desigualdades sociais, implicando em sofrimento e destruição da vida humana.

Sendo assim, a violência se mostra como uma constante social na história da humanidade, como ratifica Takeuti (2002) quando diz que a violência sempre fez parte dos diferentes padrões de sociabilidade. Essa dinâmica social do homem com a violência se modifica de acordo com a época em que este se encontra. Isto é, em cada momento histórico se configura uma significação para o fenômeno da violência. 
Esta autora ainda argumenta que nas sociedades antigas e primitivas, a violência era inscrita na lógica social, e estava vinculada harmonicamente à relação entre o homem, à natureza e a cultura, o que garantia a manutenção da ordem social. Já na sociedade contemporânea a violência é vista e apreendida como um elemento de desordem social. Logo, um elemento desestruturante e criminalizado pela sociedade e pelo Estado. Daí advém, os abrigamentos de jovens.

De antemão, ressalta-se que, as áreas da psicologia e da educação tem chamado a atenção para os efeitos negativos da violência sobre seres humanos em formação - as crianças e jovens. Deslandes (1994), Guerra (1998), Araújo (2002), Weber (2004) e que esta traz consequências às demais fases da vida.

O primeiro levantamento bibliográfico sobre violência, no Brasil, foi realizado no início da década de 1980. O que estava em foco, nesse levantamento, era o tema do "menor institucionalizado." Assim, verificou-se que nesta década, o assunto mais abordado pelos sociólogos foi a 'delinquência juvenil' e seus sinônimos 'marginalidade', 'criminalidade', 'pequenos bandidos', 'infração e menor'. Já na área da saúde predominaram os estudos sobre suicídios e o de mortes e acidentes decorrentes da violência. Esses estudos foram produzidos por clínicos e epidemiologistas.

Para Abramovay (2002) a violência juvenil tem emergido sob diversas lógicas. E destaca dois pontos para entender essa realidade, de um lado - uma forma de os jovens quebrarem com sua invisibilidade e mostrarem-se capazes de influir nos processos sociais e políticos da América Latina. Em detrimento de uma sociedade que camufla as mobilidades e segregações sociais de setores da população, principalmente dos mais pobres. Dessa forma, não reconhecem e ainda estigmatizam os principais canais de participação da juventude, como é o caso de grupos de rappers, bem como não oferecem aquilo a que os jovens tem direito como educação para o trabalho, para a produção de suas próprias existências. Sem a interferência estatal naquilo que seria preventivo, a violência emerge como meio de chamar a atenção para a realidade juvenil.

De outro lado, observa-se uma crise nas instituições socializadoras e de orientação normativa, que permitem a utilização da violência como mecanismo eficiente na resolução de conflitos para obtenção de benefícios de forma fraudulenta, a exemplo da corrupção em instituições públicas. É neste modelo societário que, ancora-se a construção de um contínuo de modelos de sociabilidade que tem na violência seu alicerce e que os jovens incorporam de forma alienada às suas vivências.

São várias as manifestações de violência juvenil, e ela tem a escola como o lugar privilegiado para as manifestações violentas. Essas podem ser conjugadas em dois grupos de agressões: as dirigidas ao patrimônio público (ao prédio escolar) e as que têm como alvo as pessoas (alunos, professores, diretores, funcionários etc). Abramovay (2002) argumenta também que a experiência de processos de exclusão e desigualdades sociais, além de gerar privações materiais, provoca entre os indivíduos a erosão dos laços de solidariedade. Nesse sentido, as redes de coesão social que estão fragilizadas colaboram para o ingresso perverso a espaços restritos de pertencimento, como é o caso de quadrilhas de tráfico de drogas e de armas, gangues etc. Mas, essa autora enfatiza que, não se pode pensar apenas nessa vulnerabilidade que coloca a violência associada à pobreza, pois estanão é sua consequência direta, mas, sim, uma forma de apresentar as desigualdades sociais e a negação do direito ao acesso a bens sociais, econômicos e culturais, que operam nas 
especificidades de cada grupo social, desencadeando assim, os atos de violência, inclusive, a desvalorização do espaço escolar, por ser este um espaço formal para educar/socializar. Entretanto, é importante salientar que a violência não é a única expressão da afirmação social da juventude, pois esta também pode se expressar através do esporte, de atividades lúdicas etc. e, nessas expressões a escola poderia contribuir de forma substancial.

As justificativas para o surgimento e proliferação das diversas manifestações de violência nas escolas aparecem atreladas tanto a fatores internos quanto externos às unidades escolares. Com relação aos fatores internos estão vinculadas às deficiências na relação entre profissionais da educação/alunos/comunidade e a pouca valorização dada pela família, pela sociedade e pelo Estado - à educação. Autores como Sposito (1992) argumentam que a violência nas escolas é uma expressão de repulsão às modalidades de agressão vividas pelos jovens no processo pedagógico, advindas de medidas disciplinares e castigos praticados por professores. (apud WAISELFISZ, 2003). Isto se enquadra naquilo que Bourdieu (1992) denominou de violência simbólica. Já na categoria dos fatores externos, as causas socioeconômicas parecem preponderantes, e nesse caso, as justificativas se encontram no sentimento de exclusão e inutilidade sentida pelos jovens (SEFFRIN, 1997, apud WAISELFISZ, 2003), o que vai incidir não só sobre as práticas de violência cometidas pelos jovens, mas também sobre as sofridas por eles.

Waiselfisz (20013) descreve que as vítimas de óbitos por armas de fogo por idades aumentaram, e ao analisar a evolução da mortalidade no período de 1980 a 2010, aponta que o crescimento da mortalidade entre os jovens foi mais intenso que no resto da população. De um modo geral, para todas as idades o crescimento foi de $346,5 \%$ ao longo do período, entre os jovens esse crescimento foi de $414,0 \%$. Outro dado informado é sobre os homicídios juvenis que cresceram de forma mais acelerada, entre o total da população que foi de $502,8 \%$, e que entre os jovens o aumento foi de 591,5\%. Esses dados sinalizam tanto para a violência sofrida pelos jovens.

É preciso redizer que a violência é contrária a ética, pois desqualifica seres humanos dotados de razão e sensibilidade, de liberdade, reduzindo-os a coisas, mudas e inertes, aqui verificada na mortalidade de jovens no país no Século XXI. Assim, reverbera-se que a violência vai além do estrago físico, atinge também outras dimensões da vida humana, pois são envolvidas por ações que comportam humilhação, vergonha, discriminação, que hoje, já são reconhecidas como condutas violentas, bem como de uma sociedade de velhos produzida pela falta de jovens. Outras formas que perpassam a violência interpessoal ou intersubjetiva incorporam a violência social, caracterizada pela falta de condições básicas de sobrevivência, que ameaçam a vida como a fome, a miséria, a exclusão. Propõe-se, por essas vias que existe violência quando tratamos sujeitos jovens - seres humanos livres, racionais - como coisas, quando não lhe são dadas as condições de existência necessárias ao seu desenvolvimento como humano/social.

Agudelo (1990, p. 04) afirma que a violência "representa um risco para a efetivação do processo vital humano, pois ameaça a vida, desfigura a saúde, causa enfermidade e provoca a morte como uma realidade ou possibilidade próxima". Assim, a violência sofrida e praticada pelos jovens não deve ser vista apenas como um problema familiar, legal, estatal e de justiça, mas também como um problema da sociedade e do Estado que sofre hoje e sofrerá no futuro as consequências do descaso com os jovens.

Dessa forma, pode-se dizer que as práticas conflituosas, carregadas de violência vivenciadas pelos jovens culminam em criminalização. Contudo, é o reflexo dos conflitos existentes não apenas 
no contexto social em que os jovens vivem, mas também nos conflitos de existência dos próprios jovens, que muitas vezes, apreendem que apenas a partir da violência conseguirão deixar sua marca no mundo, embora de forma contrária aos princípios éticos.

\section{CONSIDERAÇÕES FINAIS}

A violência é um fenômeno complexo, histórico e culturalmente construído nas relações sociais desde os primórdios da sociedade Ocidental. Refere-se a uma conduta de abuso de poder, que envolve situações de força, de tensão e desigualdade social, que implica em sofrimento e destruição. Entende-se que essas práticas de violência são construídas a partir de ações que se configuram em comportamentos sociais aéticos vivenciados, principalmente, pelos jovens seres humanos durante a construção de sua formação na família, na escola e na sociedade, espaços de socialização.

Essas reflexões conduzem a imaginar que não se pode reduzir a violência apenas às consequências físicas, ela atinge também o desenvolvimento psíquico e moral, e ainda que, essa seria também o desrespeito, a coisificação, a negação do outro, a violação dos direitos dos jovens como seres sociais e humanos. Desse modo, pode-se dizer que, a falta de reconhecimento de práticas violentas acarreta o não desenvolvimento pleno dos indivíduos, criando uma relação institucionalizada de subordinação social, que vai também além da violência psicológica, caracterizando-se como um impedimento ao direito de interagir e de desenvolver-se socialmente de modo pleno.

Ressalta-se que, o sofrimento causado por violência física pode ser comumente associado à passividade e sujeição, mas, que esse pode também provocar reação, levando a pessoa a abandonar a posição passiva de objeto do outro, situação vivida pelos jovens do Brasil que vivem em contextos de violência e são marcados pelos maus tratos sofridos conforme dados estatísticos divulgados por órgãos oficiais. Isso não significa dizer que eles não possam superar estes difíceis acontecimentos em suas vidas, mas para isto, é necessário uma reelaboração da representação do sofrimento por meio de ações socializadoras.

Portanto, propõe-se que essas ações se configurem em políticas públicas estruturantes para a juventude brasileira, que se coadunem à prática social dos jovens como forma de se expressarem no mundo social, reflexo em si de uma sociedade que enfrenta na atualidade uma crise na forma de educar e compreender a relação entre formação/educação no processo de socialização de instituições sociais como a família e a escola. Considera-se por fim que a violência vivenciada pelos jovens tem consequências e repercussões em suas vidas. Desse modo, requer compreendê-la como prática social aética, como um impedimento de fato; uma ação contrária a qualquer processo socializador.

\section{REFERÊNCIAS}

1. ABRAMOVAY, Miriam. Violência nas escolas. Abramovay, M. etall. Brasília: UNESCO, Coordenação DST/AIDS do Ministério da Saúde, a Secretaria de Estado dos Direitos Humanos do Ministério da Justiça, CNPq, Instituto Ayrton Senna, UNAIDS, Banco Mundial, USAID, Fundação Ford, CONSED, UNDIME, 2002.

2. ABRAMOVAY, Miriam; FEFFERMANN, Marisa. Juventude e sociabilidade vivendo uma cultura 
de violência. Disponível em: file://C:/Users/usuario/Downloads/Juventude\%20e\%20sociabili dade,\%20vivendo\%20uma\%20cultura\%20de\%20viol\%C3\%AAncia\%20-\%20artigo\%20revista\%20miriam\%20e\%20marisa1.pdf. Acesso em outubro de 2014.

3. ADORNO, S. Violência e educação. Trabalho apresentado no 5o Simpósio Municipal de Educação, mimeo, Caxias do Sul, Rio Grande do Sul, 1988.

4. AGUDELO, S. F. La Violência: um problema de salud pública que se agrava em laregión. BoletinEpideniologico de la OPS, 1990.

5. ARENDT, Hannah. Sobre a violência. Tradução de André Duarte. Rio de Janeiro: RelumeDamara, 1994.

6. BAUMAN, L. J.; FRIEDMAN, S.B. Corporal punishment. In: Pediatric clinics of north America. v. $45, \mathrm{n} 2,1998$.

7. BLOCH, Ernest. O princípio esperança. 1. ed. Rio de Janeiro, EDUERJ: Contraponto; 2005, v.1.

8. BOURDIEU, Pierre; PASSERON, Jean-Claude.A reprodução: elementos para uma teoria do sistema de ensino. São Paulo: Francisco Alves, 1992.

9. CHAUÍ, M. Participando do debate sobre mulher e violência. In_. CARDOSO, R. (Org.) Perspectivas antropológicas da mulher: sobre mulher e violência. Rio de Janeiro: Zahar, v. 4. p. 25-62, 1997.

10. Cultura e Democracia: o discurso competente e outras falas. São Paulo: Cortez, 2006.

11. DESLANDES, S. F. Atenção a crianças e adolescentes vítimas de violência doméstica. Análise de um serviço. Cadernos de Saúde Pública, 1994, 10: 177-187.

12. EVANGELISTA, Dalmo de Oliveira. Sem eira, nem beira: adolescentes em conflito com a lei e as políticas públicas de atendimento. Revista Inter-legere; ano 1; no1; Jan/jul, 2007.

13. FERREIRA, Ruth Vasconcellos Lopes. A cultura da violência em Alagoas: Um estudo em Representação Social. Tese de Doutorado. Recife: Universidade Federal de Pernambuco, Programa de Pós-graduação em Sociologia, 2002.

14. FALLUH, Santiago. O levantamento de informações sobre direitos violados de crianças e adolescentes no Sistema de Informações para Infância e Adolescência (SIPIA - módulo I): conteúdo e metodologia. Texto para discussão n. 1012 - IPEA, Brasília, março de 2004.

15. KAUFMAN, Michael. The construction of masculinity and the triado $f$ men's violence.In_.Gender violence: interdisciplinary perspectives. (Org.) Laura L. O'toole, Jessica R. Schiffman. New York: New York Universitypress, 1997.

16. MALDONADO, Daniela P. A.; WILLIAMS, Lúcia C. de A. O comportamento agressivo de crianças do sexo masculino na escola e sua relação com a violência doméstica. Psicologia e Estudos. v. 10, n. 03, Maringá, set/dez, 2005.

17. MINAYO, M. C. S. \& ASSIS, S. G. Violência e saúde na infância e adolescência: uma agenda de investigação estratégica. Saúde em Debate, 39: 58-63, 1993.

18. SANTOS, Boaventura de Sousa. Conhecimento prudente para uma vidadecente: Um discurso sobre a ciência revisitado. São Paulo, Cortez; 2004.

19. SOUZA, Adriana A. de. As vivências da violência intrafamiliar: Osimbolismo dos desenhos infantis. Tese. Universidade Federal do Rio Grande do Norte. Centro de Ciências Humanas, 
Letras e Artes. Programa de Pós-graduação em Ciências Sociais, Natal, 2013, 189 f.

20. TAKEUTI, Norma Missae. No outro lado do espelho: a fratura social e as pulsões juvenis. Rio de janeiro: RelumeDumará; Natal: Universidade Federal do Rio Grande do Norte, 2002.

21. WAISELFISZ, JulioJacobo. Mapa da violência 2013 Mortes Matadas por Armas de Fogo. Centro Brasileiro de Estudos Latinos-Americanos/FRACSO, 2013. Disponível em: www. fracso.org.br. Acesso em: maio de 2014. 